\title{
Silver-loaded nanoparticles affect ex-vivo mechanical behavior and mineralization of dentin
}

\author{
Manuel Toledano ${ }^{1}$, Fátima S. Aguilera ${ }^{1}$, Inmaculada Cabello ${ }^{2}$, Manuel Toledano-Osorio ${ }^{3}$, Estrella Osorio ${ }^{1}$, \\ Modesto T. López-López ${ }^{4}$, Franklin García-Godoy ${ }^{5}$, Christopher D. Lynch ${ }^{6}$, Raquel Osorio ${ }^{1}$
}

\author{
${ }^{1}$ DDS, PhD, Professor. Dental Materials Section, University of Granada, Faculty of Dentistry, Colegio Máximo de Cartuja s/n, \\ Granada, Spain \\ ${ }^{2} \mathrm{DDS}, \mathrm{PhD}$, Research Fellow. Dental Materials Section, University of Granada, Faculty of Dentistry, Colegio Máximo de Car- \\ tuja s/n, Granada, Spain \\ ${ }^{3}$ Research Fellow. Dental Materials Section, University of Granada, Faculty of Dentistry, Colegio Máximo de Cartuja s/n, \\ Granada, Spain \\ ${ }^{4}$ DDS, PhD, Professor. University of Granada, Faculty of Science, Applied Physics Department. Fuente Nueva s/n $18071-$ \\ Granada - Spain \\ ${ }^{5}$ DDS, MS, PhD, Professor. Bioscience Research Center, College of Dentistry, University of Tennessee, Health Science Center, \\ 875 Union Avenue, USA \\ ${ }^{6}$ BDS, PhD, Professor. University Dental School \& Hospital/ University College Cork, Wilton, Cork - Ireland
}

Correspondence:

University of Granada, Faculty of Dentistry

Colegio Máximo de Cartuja s/n

18071 - Granada, Spain

mtoledano@correo.ugr.es

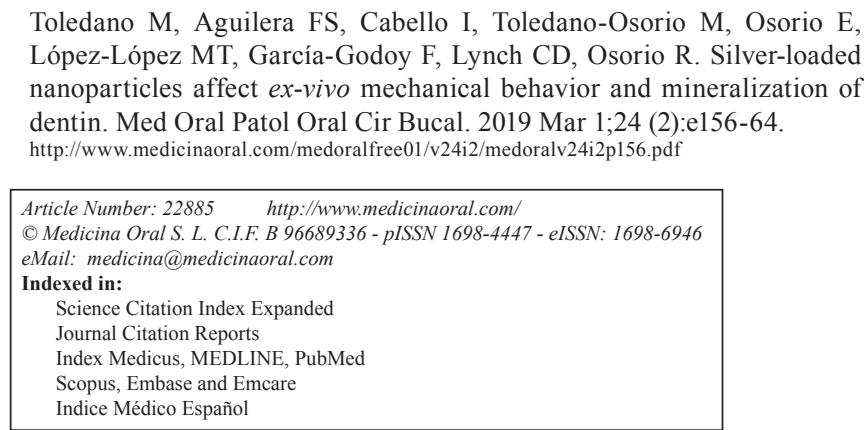

Toledano M, Aguilera FS, Cabello I, Toledano-Osorio M,
López-López MT, García-Godoy F, Lynch CD, Osorio R. S
nanoparticles affect ex-vivo mechanical behavior and mine
dentin. Med Oral Patol Oral Cir Bucal. 2019 Mar 1;24 (2):e156-
http://www.medicinaoral.com/medoralfree01/v24i2/medoralv24i2p156.pdf
Article Number: 22885 http://www.medicinaoral.com/
O Medicina Oral S. L. C.I.F. B 96689336 - pISSN 1698-4447 - eISSN: 1698-6946
eMail: medicina@medicinaoral.com
Indexed in:
Science Citation Index Expanded
Journal Citation Reports
Index Medicus, MEDLINE, PubMed
Scopus, Embase and Emcare
Indice Médico Español

\begin{abstract}
Background: The aim was to evaluate the effect of silver loaded nanoparticles (NPs) application on the triboscopic, crystallographic and viscoelastic properties of demineralized dentin. Polymethylmetacrylate-based NPs and Ag loaded NPs were applied on demineralized dentin.

Material and Methods: Treated and untreated surfaces were probed by a nanoindenter to test viscoelasticity, and by atomic force microscopy to test nanoroughness and collagen fibril diameter. X-ray diffraction and transmission electron microscopy through selected area diffraction and bright-field imaging were also used.

Results: Dentin treated with Ag-NPs attained the lowest complex modulus, and the highest tan delta values after 7 days of storage. Dentin treated with undoped-NPs achieved the lowest nanoroughness and the greatest collagen bandwidths among groups. Crystals were identified as hydroxyapatite with the highest crystallographic maturity and crystallite size in dentin treated with undoped-NPs. Texture increased in all samples from $24 \mathrm{~h}$ to $7 \mathrm{~d}$, except in dentin surfaces treated with Ag-NPs at 310 plane. Polyhedral, block-like, hexagonal or plate-like shaped apatite crystals constituted the bulk of minerals in dentin treated with Ag-NPs, after $7 \mathrm{~d}$. Polyhedral or rounded/drop-like, and polymorphic in strata crystal apatite characterized the minerals when undoped-NPs were used, with more
\end{abstract}


crystalline characteristics after $7 \mathrm{~d}$ than that found when Ag-NPs were applied. Ag-NPs application did not improve the mechanical performance of dentin and did not produce dentin remineralization. However, energy was dissipated through the dentin without showing stress concentration; contrary was occurring at dentin treated with undopedNPs, that provoked bridge-like mineral deposits at the dentin surface.

Conclusions: Ag-NPs application did not enhance the mechanical properties of cervical dentin, though the energy dissipation did not damage the dentin structure. Remineralization at dentin was not produced after Ag-NPs application, though improved crystallinity may lead to increase stability of the apatite that was generated at the dentin surface.

Key words: Dentin, mechanical, mineralization, roughness, silver, viscoelastic.

\section{Introduction}

To facilitate dentin remineralization and antimicrobial characteristics, dentin infiltration with cytocompatible polymeric nanoparticles (NPs), such as calcium and phosphate sequestering materials have been previously proposed (1-3). Silver has been included into some dentin adhesive formulations (3) as it has demonstrated to be an effective antimicrobial, able to promote caries arrestment and to prevent biofilm formation (4). NPsloaded with Ag play an important role in the disinfection of dentinal tubules (5).

In most of the previous studies, there is a lack of information dealing with the beneficial or harmful effects of silver on hard tissues regeneration with apparent inconsistencies in the results obtained. Silver not only provides an antibacterial effect, but biochemical inertness (6). To date, only a few studies have focused on the effect of silver on bone regeneration associated with implanted materials (7). Nevertheless, recently, Dong et al., 2017 (8) described a bridge formed with new bone occupying a big area of a cranial created defect, after a gelatin-Ag application (8).

Ag-NPs regulate the deposition of collagen and inhibit uncontrolled growth of collagen, as well as directing proper collagen matrix alignment and spatial arrangement (9). Although there are few studies of $\mathrm{Zn}$ or Caloaded NPs $(1,2)$ on dentin, the effects of Ag-NPs on the dynamic mechanical properties and physic-chemical characterization of treated dentin are unknown.

Nano-dynamic mechanical analysis (Nano-DMA), atomic force microscopy (AFM) analysis, X-ray diffraction (XRD), transmission electron microscopy (TEM) and selected area electron diffraction (SAED) were combined to examine the new formed dentin under the effects of silver. Therefore, the purpose of this study was to assess the effect of Ag-NPs on the triboscopic properties, and both crystallographic and viscoelastic performance of cervical dentin. The null hypothesis that was established is that $\mathrm{Ag}$ is not able to create differences in dynamic mechanical performance, triboscopic properties and crystal morphology of dentin.

\section{Material and Methods}

-Nanoparticles production and specimens' preparation PolymP-n Active nanoparticles (NPs) (NanoMyP, Granada, Spain) were fabricated through polymerization precipitation (10). NPs are composed by 2-hydroxyethyl methacrylate (backbone monomer), ethylene glycol dimethacrylate (cross-linker) and methacrylic acid (functional monomer). For silver complexation, $30 \mathrm{mg}$ of NPs were immersed at room temperature, during 3 days under continuous shaking in $15 \mathrm{ml}$ aqueous solution of $\mathrm{AgNO}_{3}$ (containing $\mathrm{Ag}$ at $40 \mathrm{ppm}$ at $\mathrm{pH}$ 6.5), in order to reach the adsorption equilibrium of metal ions. Two different NPs were produced: 1) undoped-NPs (NPs), 2) NPs doped with Ag (Ag-NPs). Nine sound, human single-rooted teeth were obtained with informed consent from donors (18 to $25 \mathrm{yr}$ of age), under a protocol approved by the Institution review board (\#405/ CEIH/2017). From each tooth, two dentin blocks were obtained from the buccal surface of the root, just below the cementodentinal junction. The tooth was cut perpendicular to the axial axis using a diamond saw (Accutom-50 Struers, Copenhagen, Denmark) under copious water irrigation to obtain cementodentinal slabs with a thickness of $1 \mathrm{~mm}$. Specimens were then prepared as in Toledano-Osorio et al., 2018 (11). A phosphate buffered suspension (PBS) of NPs $(10 \mathrm{mg} / \mathrm{ml})$, Ag-NPs $(10 \mathrm{mg} /$ $\mathrm{ml})$ or just a PBS solution were applied (30 s), in each of the three different experimental groups. Half of the specimens were tested after storing in PBS at $37^{\circ} \mathrm{C}$ for 24 hours and the other half after 7 days.

-Nano-DMA and Atomic Force Microscopy (AFM) analysis

Blocks of each treated dentin were subjected to nanoDMA and AFM analyses. Nanomechanical properties were assessed by means of a Hysitron Ti Premier nanoindenter (Hysitron, Inc., Minneapolis, MN), a commercial nano-DMA package. A dynamic (oscillatory) force of $2 \mu \mathrm{N}$ was superimposed on the quasistatic signal at a frequency of $200 \mathrm{~Hz}$. Modulus mapping of our samples was conducted by imposing a quasistatic force setpoint, $\mathrm{Fq}=2 \mu \mathrm{N}$, to which we superimposed a sinu- 
soidal force of amplitude $\mathrm{FA}=0.10 \mu \mathrm{N}$ and frequency $\mathrm{f}=100 \mathrm{~Hz}$. Data from regions approximately $10 \times 10 \mu \mathrm{m}$ in size were collected using a scanning frequency of $0.2 \mathrm{~Hz}$. The rest of the procedures was as in ToledanoOsorio et al. (2018). On the same surfaces, an atomic force microscope (AFM Nanoscope V, Digital Instruments, Veeco Metrology group, Santa Barbara, CA, USA) was employed for topography mappings. A $10 \mathrm{~nm}$ radius silicon nitride tip (Veeco) was attached to the end of an oscillating cantilever that came into intermittent contact with the surface at the lowest point of the oscillation. Changes in vertical position of the AFM tip at resonance frequencies near $330 \mathrm{kHz}$ provided the height of the images registered as bright and dark regions. 10 x $10 \mu \mathrm{m}$ digital images were recorded from each dentin surface, with a slow scan rate $(0.1 \mathrm{~Hz})$. For each image, 5 randomized boxes $(1 \mathrm{x} 1 \mu \mathrm{m})$ were created to examine the intertubular dentin (ID) and peritubular dentin (PD) nanoroughness at $24 \mathrm{~h}$ and $7 \mathrm{~d}$ of storage. Nanoroughness (SRa, in nanometers) and the collagen fibril diameter was determined as in Toledano et al., 2018 (12). As the normality and homoscedasticity assumptions of the data were valid, numerical data were analyzed with ANOVA and Student-Newman-Keuls multiple comparison tests, with statistical significance preset at $p<0.05$.

- X-Ray Diffraction (XRD) and Transmission Electron Microscopy (TEM) analysis

Treated surfaces were submitted to XRD analysis. The X-ray micro-diffractometer $\left(\mu \mathrm{XRD}^{2}\right)$ used in this study was a single crystal diffractometer with a 2-dimensional detector system Cmos Photon 100 (Bruker-D8 Venture, Wien, Austria), equipped with kappa geometry based goniometer 2D Detector and XRD 2D Scan software. The X-ray beam $(\mathrm{Cu} \mathrm{K} \alpha$ line, $\lambda=$ $1.5418 \AA$ ) was generated by a $\mathrm{Cu}$ Microforms source I $\mu$ s and generator settings of $50.00 \mathrm{kV} / 1.00 \mathrm{~mA}$ were employed. The sample to detector distance was 40.00 $\mathrm{mm}, 2 \Theta$ scanning angle range was from $10^{\circ}$ to $80^{\circ}$. For TEM analysis, dentin samples were crushed into a finegrained powder in a liquid nitrogen mortar and pestle, and $2 \% \mathrm{NaOCl}$ was added to remove the surrounding collagen, with daily changes for a week (using a sonicator). Stack images were acquired, and the position of the stage was changed between -40 and $+50^{\circ}$ of $\alpha$ tilt, and collected every $10^{\circ}$. The samples were analyzed using a Transmission Electron Microscope Zeiss Libra 120 (Oberkochen, Germany) at $120 \mathrm{kV}$ in bright-field (BF), and selected area electron diffraction (SAED) patterns were also captured. The rest of the procedure was as in Toledano et al., 2018 (2).

\section{Results}

- Nano-DMA analysis and Atomic Force Microscopy (AFM) analysis

The nano-DMA properties of the cervical dentin sur- faces at PD and ID were influenced by the type of NPs applied $(P<0.05)$ and by the storage time $(P<0.05)$. Interactions between factors were also significant $(P<0.05)$. Mean and SD of complex modulus $\left(E^{*}\right)$, tan delta $(\delta)$, storage modulus $\left(E^{\prime}\right)$ and loss modulus $\left(E^{\prime \prime}\right)$ are represented in Table 1 and Figs. 1A-1D. Complex modulus $\left(E^{*}\right)$ assessed at $24 \mathrm{~h}$ of storage attained the lowest values at ID surfaces treated with undoped-NPs. At PD, undoped-NPs achieved the lowest $E^{*}$ at $24 \mathrm{~h}$ of storage, and dentin treated with Ag-NPs attained the lowest $E^{*}$ among groups, at $7 \mathrm{~d}$ (Table 1, Fig. 1A). After $7 \mathrm{~d}$ of storage, untreated dentin achieved the lowest $\delta$ at ID, and at PD Ag-NPs attained the highest $\tan \delta$ values. Negligible data were presented at ID treated with AgNPs at $24 \mathrm{~h}$, and at PD treated with undoped-NPs and $\mathrm{Ag}-\mathrm{Nps}$ at $24 \mathrm{~h}$ of storage. An increase of $\tan \delta$ in dentin treated with Ag-NPs was also observed at $24 \mathrm{~h}$. Similar trend was followed at PD (Table 1).

Nanoroughness (SRa) of dentin surfaces was influenced by the type of NPs applied $(P<0.05)$ and by the storage time $(P<0.05)$; interactions between factors were also significant $(P<0.05)$. Mean and SD of nanoroughness are presented in Table 2A. The bandwidth of the collagen fibrils were also influenced by the type of NPs applied $(P<0.05)$ and by the storage time $(P<0.05)$; interactions between factors were also significant $(P<0.05)$. Mean and SD of the fibrils width are presented in Table 2B. At both $24 \mathrm{~h}$ and $7 \mathrm{~d}$ time points, dentin treated with undoped-NPs attained the greatest bandwidths among groups.

-X-Ray Diffraction (XRD) and Transmission Electron Microscopy (TEM) analysis

The analysis of $\mu \mathrm{XRD}^{2}$ profiles of cervical dentin showed that the physical broadening full width half maximum (FWHM) of peaks at $002\left(2 \Theta, 25.900^{\circ}\right.$; centroid peak position $\Theta_{\mathrm{hkl}}, 0 / 0 /-2$; I, 10977386) reflection, after observing data plotted by the reduced full width and extended height at half maximum of the phosphate band, was higher ( 1.1 fold) in untreated dentin surfaces when compared with the treated groups, after $7 \mathrm{~d}$ of PBS storage. When dentin was treated with undoped-NPs, after observing the reflection at 211 peak and the diffraction ring corresponding to 211 and 112 planes (Fig. 2 , inset $b$ ), it may be noted higher crystallinity values than those obtained after assessing untreated (Fig. 2, inset a) and Ag-NPs treated dentin (Fig. 2, inset c). This was confirmed after observing the Table 3. A qualitative estimation of the size of the coherently scattering domain (i.e. the crystallite size) is reported in Table 3. The shortest $[\tau 002(\mathrm{H})](9.185 \mathrm{~nm})$ and narrowest $[\tau 310$ (L)] $(4.57 \mathrm{~nm})$ crystallite size, after $7 \mathrm{~d}$ of storage, corresponded to the untreated dentin (Table 3). In the group of dentin treated with Ag-NPs, the dentin crystals attained the highest grain size [10.25 nm ( $\tau 002), 4.94 \mathrm{~nm}$ ( 2310$)]$ (Table 3). Texture indices ( $\mathrm{R} h k l$ ) in dentin poly- 
Table 1. Mean and standard deviation (SD) of Complex Modulus (GPa), tan $\delta$, storage ( $E^{\prime}$ ) and loss ( $\left.E^{\prime \prime}\right)$ modulus (GPa) attained for experimental dentin-treated surfaces.

\begin{tabular}{|c|c|c|c|c|c|c|c|c|}
\hline & & \multicolumn{3}{|c|}{ Untreated } & \multicolumn{2}{|c|}{ NPs } & \multicolumn{2}{|c|}{ Ag-NPs } \\
\hline & & $4 \mathrm{~h}$ & $7 d$ & $24 h$ & $7 d$ & $24 h$ & $7 d$ & \\
\hline \multirow{2}{*}{$\begin{array}{c}\mathrm{CM} \\
(\mathrm{GPa}) \\
\text { Mean } \\
(\mathrm{SD})\end{array}$} & PD & $\begin{array}{c}185.33 \\
(47.09) \\
A^{*}\end{array}$ & \multicolumn{2}{|c|}{$\begin{array}{c}308.16 \\
(53.33) \\
\mathrm{a}\end{array}$} & $\begin{array}{c}123.74 \\
(25.62) \\
A^{*}\end{array}$ & $\begin{array}{c}349.42 \\
(35.87) \\
\mathrm{a}\end{array}$ & $\begin{array}{c}174.68 \\
(46.94) \\
\text { A }\end{array}$ & $\begin{array}{c}154.09 \\
(73.41) \\
b\end{array}$ \\
\hline & ID & $\begin{array}{c}99.40 \\
(12.65) \\
\text { A }\end{array}$ & \multicolumn{2}{|c|}{$\begin{array}{c}94.38 \\
(21.17) \\
a\end{array}$} & $\begin{array}{c}69.95 \\
(17.54) \\
B^{*}\end{array}$ & $\begin{array}{c}143.89 \\
(24.62) \\
\mathrm{b}\end{array}$ & $\begin{array}{c}80.06 \\
(21.36) \\
\text { A }\end{array}$ & $\begin{array}{c}60.89 \\
(10.35) \\
c\end{array}$ \\
\hline \multirow{2}{*}{$\begin{array}{l}\text { Tan } \\
\text { Delta } \\
\text { Mean } \\
\text { (SD) }\end{array}$} & PD & $\begin{array}{c}0.09 \\
(0.009) \\
\mathrm{A}^{*}\end{array}$ & \multicolumn{2}{|c|}{$\begin{array}{c}0.009 \\
(0.00007) \\
a\end{array}$} & $\mathrm{x}$ & $\begin{array}{c}0.01 \\
(0.001) \\
\mathrm{a}\end{array}$ & $\mathrm{x}$ & $\begin{array}{c}0.019 \\
(0.006) \\
b\end{array}$ \\
\hline & ID & $\begin{array}{c}0.24 \\
(0.03) \\
A^{*}\end{array}$ & \multicolumn{2}{|c|}{$\begin{array}{c}0.03 \\
(0.003) \\
\mathrm{a}\end{array}$} & $\begin{array}{c}0.07 \\
(0.003) \\
B^{*}\end{array}$ & $\begin{array}{c}0.05 \\
(0.001) \\
\mathrm{b}\end{array}$ & $\mathrm{x}$ & $\begin{array}{c}0.07 \\
(0.008) \\
\mathrm{c}\end{array}$ \\
\hline \multirow{2}{*}{$\begin{array}{c}\mathrm{SM}\left(E^{\prime}\right) \\
(\mathrm{GPa}) \\
\text { Mean } \\
(\mathrm{SD})\end{array}$} & PD & $\begin{array}{c}142.80 \\
(49.44) \\
A^{*}\end{array}$ & \multicolumn{2}{|c|}{$\begin{array}{c}296.69 \\
(26.10) \\
a\end{array}$} & $\begin{array}{c}130.06 \\
(40.60) \\
A^{*}\end{array}$ & $\begin{array}{c}283.88 \\
(30.40) \\
\mathrm{a}\end{array}$ & $\begin{array}{c}198.70 \\
(49.97) \\
\text { A }\end{array}$ & $\begin{array}{c}178.83 \\
(46.26) \\
b\end{array}$ \\
\hline & ID & $\begin{array}{c}149.49 \\
(59.78) \\
\text { A }\end{array}$ & \multicolumn{2}{|c|}{$\begin{array}{c}117.16 \\
(31.41) \\
a\end{array}$} & $\begin{array}{c}60.33 \\
(16.02) \\
B^{*}\end{array}$ & $\begin{array}{c}160.72 \\
(33.55) \\
\mathrm{a}\end{array}$ & $\begin{array}{c}92.15 \\
(22.38) \\
\text { B }\end{array}$ & $\begin{array}{c}92.70 \\
(18.92) \\
\mathrm{b}\end{array}$ \\
\hline \multirow{2}{*}{$\begin{array}{c}\mathrm{LM}(E ”) \\
(\mathrm{GPa}) \\
\text { Mean } \\
(\mathrm{SD})\end{array}$} & PD & $\begin{array}{c}8.17 \\
(1.29) \\
A^{*}\end{array}$ & \multicolumn{2}{|c|}{$\begin{array}{c}11.92 \\
(0.60) \\
a \\
\end{array}$} & $X$ & $\begin{array}{c}5.99 \\
(1.01) \\
b\end{array}$ & $X$ & $\begin{array}{c}2.91 \\
(0.82) \\
\mathrm{c}\end{array}$ \\
\hline & ID & $\begin{array}{c}10.20 \\
(2.45) \\
A^{*}\end{array}$ & \multicolumn{2}{|c|}{$\begin{array}{c}2.90 \\
(0.74) \\
a\end{array}$} & $\begin{array}{c}2.11 \\
(0.29) \\
B\end{array}$ & $\begin{array}{c}2.55 \\
(0.52) \\
\mathrm{a}\end{array}$ & $\mathrm{X}$ & $\begin{array}{c}2.15 \\
(0.29) \\
\mathrm{a}\end{array}$ \\
\hline
\end{tabular}

Abbreviations: Ag-NPs: Ag doped nanoparticles; NPs: undoped nanoparticles; PD: peritubular dentin; ID: intertubular dentin. X: negligible data. Similar capital and lowercase letters indicate no significant differences among experimental groups ( $p<0.05$ ), at $24 \mathrm{~h}$ and $7 \mathrm{~d}$ of storage, respectively. Asterisks mean significant differences between $24 \mathrm{~h}$ and $7 \mathrm{~d}$ storage time.

crystalline structures were calculated. At 002 plane, the texture assessed at the cervical dentin treated with all NPs solutions followed the trend: untreated dentin < Ag-NPs $<$ undoped-NPs. At 310 plane, the trend was: Ag-NPs $<$ undoped-NPs $<$ untreated dentin (Table 3). After $7 \mathrm{~d}$, the untreated cervical dentin exhibited, in bright-field (BF), distinct morphologies as rounded/ drop-like crystals, polymorphic apatite crystals in strata when undoped-NPs were used and block-like or rounded apatite agglomerate crystallites when Ag-NPs were employed. They were transparent enough to observe their lattice, and also relatively stable enough for tilt series acquisition (Figs. 3A-3D). The polymorph/polyhedral crystals were confirmed to be more amorphous in nature than that organized in strata or in rounded morphologies (Fig. 3F), as observed from the diffuse ring pattern (insets at Figs. 3E, 3F).

\section{Discussion}

This study has shown for the first time that the strong interaction of Ag-NPs with HAp structure provoked poor maturation and scarce functional remineralization with ultrafine nano-crystallites at cervical dentin; these hexagonal nanoplate crystallites, with scarce crystallinity, had preferred orientation in $c$-direction with tendency to agglomerate toward random orientation.

Considering that both the storage modulus $\left(E^{\prime}\right)$ and the loss modulus ( $E$ ") (Figs. 1C, 1D) (Table 1) are involved in the viscoelastic expression of the complex modulus $\left(E^{*}\right)$ and $\tan \delta$, only $E^{*}$ and $\tan \delta$ will be discussed. The complex modulus $\left(E^{*}\right)$ is a measure of the resistance of a material to dynamic deformation (13). After $7 \mathrm{~d}$ of storage, intertubular untreated dentin and dentin treated with Ag-NPs attained similar $E^{*}$, but at peritubular dentin the lowest resistance to deformation was obtained in dentin treated with Ag-NPs (Table 1), (Fig. 1A), denoting poor functional or intrafibrillar remineralization (14). This indicates a decrease in apatite maturity and in dentin mechanical properties (15). The moderate modulus that was obtained complies with scarce peritubular mineralization and generalized open tubules (Fig. 1G). This scarce remineralization was confirmed by nanor- 
A
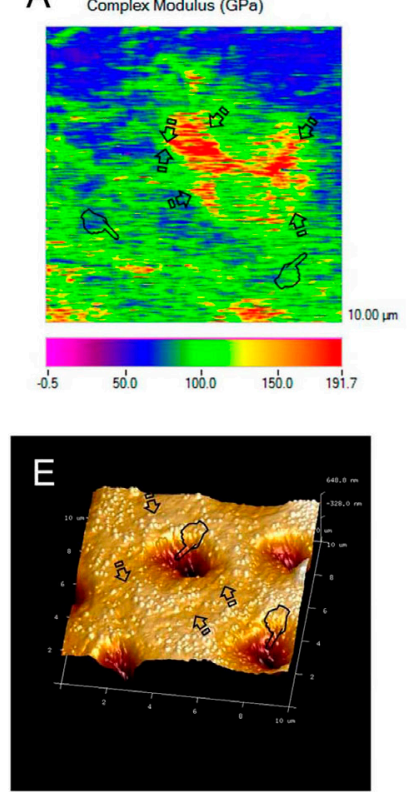

B
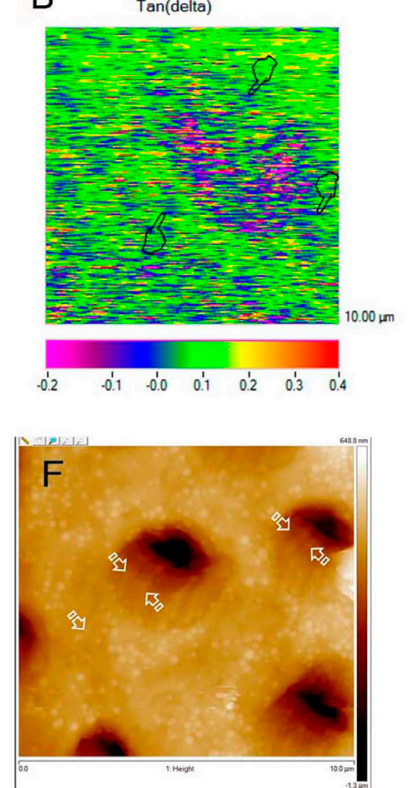

C Storage Modulus (E) (GPa)
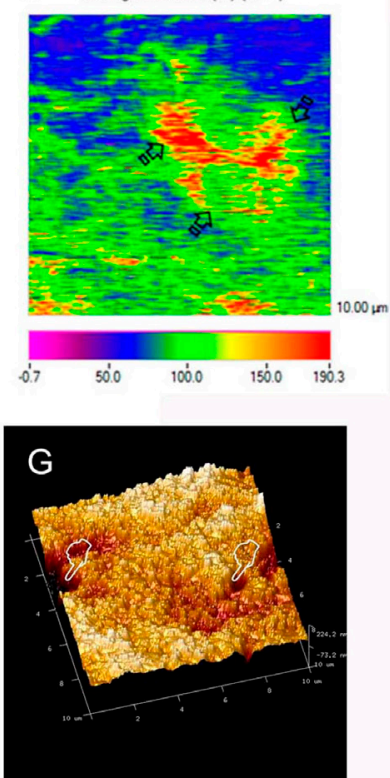

D Loss Modulus (E) (GPa)
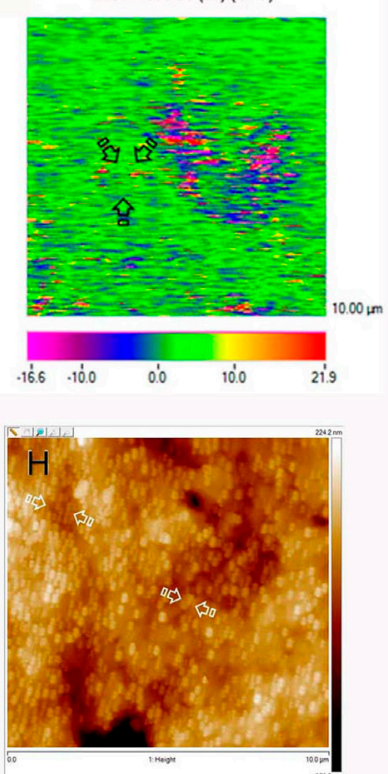

Fig. 1. Scanning mode nano-DMA analysis of the map of the complex modulus $\left(E^{*}\right)$ at the cervical dentin treated with Ag-NPs, obtained at $7 \mathrm{~d}$ (A) time point. In the color scheme shown, the red color corresponds to the highest value of the locally measured moduli, likely corresponding to the highest resistance to deformation of the peritubular dentin (arrows). $E^{*}$ referred to intertubular dentin appears in bluish green (pointers). The pixel data array at the mapping are organized according to $E^{*}$ distribution that concurs with a clear delimitation between intertubular and peritubular dentin (faced arrows). Scanning mode nano-DMA analysis of the map of the $\tan \delta$ at the cervical dentin treated with Ag-NPs, obtained at $7 \mathrm{~d}$ (B) time point. In the color scheme shown, the red color corresponds to the highest value of the locally tan $\delta$ value moduli, potentially associated to $\tan \delta$ of intertubular dentin (arrows). The capacity for getting rid of the energy ( $\tan \delta$ ) at peritubular dentin after $7 \mathrm{~d}$ of storage is represented by the blue-green diffused marks (pointers), at the mapping (B). Scanning mode nano-DMA analysis of the map of the storage modulus $\left(E^{\prime}\right)$ at the cervical dentin treated with $\mathrm{Ag}-\mathrm{NPs}$, obtained at $7 \mathrm{~d}(\mathrm{C})$ time point. In the color scheme shown, the red color corresponds to the highest value of the locally measured moduli, likely corresponding to the highest ability to stored energy of the peritubular dentin (arrows). E' referred to peritubular dentin appears in red yellowish. The pixel data array at the mapping are organized according to $E^{*}$ distribution that concurs with a clear delimitation between intertubular and peritubular dentin (arrows). Scanning mode nano-DMA analysis of the map of the loss modulus ( $\left.E^{\prime \prime}\right)$ at the cervical dentin treated with Ag-NPs, obtained at $7 \mathrm{~d}(\mathrm{D})$ time point. In the color scheme shown, the red color corresponds to the highest value of the locally ( $\left.E^{\prime \prime}\right)$ value moduli, potentially associated to loss modulus of peritubular dentin (arrows). The greatest ability of dentin to dissipate energy corresponded to peritubular dentin after $7 \mathrm{~d}$ of storage, and is represented by the dark-green areas (arrows), at the mapping. AFM $10 \times 10 \mu \mathrm{m}$ top-view and surface plot image of cervical dentin after applying Ag-NPs, at $24 \mathrm{~h}$ (E) of storage. Dentinal tubules remained visible and open (pointers). AFM heights $(10 \times 10 \mu \mathrm{m})(\mathrm{F})$ of this partially demineralized dentin surface with open dentinal tubules and very narrow fibrils width (faced arrows). AFM 10 × $10 \mu \mathrm{m}$ top-view and surface plot image of cervical dentin after applying Ag-NPs, at $7 \mathrm{~d}(\mathrm{G})$ of storage, with open dentinal tubules. AFM heights $(10 \times 10 \mu \mathrm{m})(\mathrm{H})$ of this partially demineralized dentin surface. Dentin tubules were open (pointers) and thin collagen fibrils discovered (faced arrows). The dentin surface showed much more organized structure in contrast to the loose and randomly aligned fibril matrix of the untreated samples.

oughness measurements, as dentin treated with Ag-NPs attained the highest SRa values (Table 2A). An increase in roughness is associated to poor mineral maturation and it is a sight of scarce intrafibrillar remineralization. Accordingly and contrary to the dentin treated with undoped-NPs, the fibrils width did not change when compared with the untreated group, confirming the absence of mineral gain at fibrils (Figs. 1F, 1H) (Table 2B). At both PD and ID treated with Ag-NPs, after $7 \mathrm{~d}$ of storage, no mineral deposits (Fig. 1G) and the highest tan $\delta$ values were observed (Table 1) (Fig. 1B). The greater $\tan \delta$, the lower proportion of energy available in the system for recoil and/or failure (16). Dentin treated with undoped-NPs attained both remineralization of dentin and mineral precipitation within the dentinal tubules (data not shown), but the maxima discrepant $\tan \delta$ values ( $\sim 5$ fold) when ID and PD were compared, after $7 \mathrm{~d}$ storage. In the present study, discrepancy of $\tan \delta$ values between ID and PD became potentially associated to zones and signs of energy concentration as bridgelike structures, stick-slip images, indicating sights of energy dissipation (17). Signs of energy concentration hardly appeared at the dentin surface treated with AgNPs (Fig. 1G), due to the relative higher homogeneity of viscoelastic properties.

When $\mu \mathrm{XRD}^{2}$ of dentin treated with Ag-NPs was analyzed, a FWHM decrease, nearly one order of magnitude, was observable when data from specimens stored $7 \mathrm{~d}$ were compared with the untreated samples at both 002 and 310 planes (Table 3) (Fig. 2). These sharper and 
Table 2. Mean and standard deviation (SD) of nano-roughness and fibrils width in untreated and undoped nanoparticles, Ag doped nanoparticles treated dentin.

\begin{tabular}{|c|c|c|c|c|c|c|}
\hline & \multicolumn{4}{|c|}{ A. Nano-roughness } & \multirow{2}{*}{\multicolumn{2}{|c|}{$\begin{array}{ll}\text { B. } & \text { Fibrils } \\
\text { width }\end{array}$}} \\
\hline & \multicolumn{2}{|c|}{$\begin{array}{l}\text { INTERTUBULAR DENTIN } \\
\text { (ID) }\end{array}$} & \multicolumn{2}{|c|}{$\begin{array}{l}\text { PERITUBULAR DENTIN } \\
\text { (PD) }\end{array}$} & & \\
\hline & $\begin{array}{c}24 \mathrm{~h} \\
(\mathrm{SRa}, \mathrm{nm})\end{array}$ & $\begin{array}{c}7 \text { days } \\
(\mathrm{SRa}, \mathrm{nm})\end{array}$ & $\begin{array}{c}24 \mathrm{~h} \\
(\mathrm{SRa}, \mathrm{nm})\end{array}$ & $\begin{array}{c}7 \text { days } \\
(\mathrm{SRa}, \mathrm{nm})\end{array}$ & $\begin{array}{l}24 \mathrm{~h} \\
(\mathrm{~nm})\end{array}$ & $\begin{array}{c}7 \text { days } \\
(\mathrm{nm})\end{array}$ \\
\hline Untreated & $\begin{array}{c}22.37 \\
(5.98) \\
\mathrm{a}\end{array}$ & $\begin{array}{c}29.36 \\
(2.43) \\
\mathrm{a}^{*}\end{array}$ & $\begin{array}{c}20.98 \\
(7.07) \\
\mathrm{A}\end{array}$ & $\begin{array}{c}27.75 \\
(5.27) \\
\mathrm{A}\end{array}$ & $\begin{array}{c}65.16 \\
(11.42) \\
\alpha\end{array}$ & $\begin{array}{c}63.83 \\
(11.12) \\
\alpha\end{array}$ \\
\hline Undoped-NPs & $\begin{array}{c}27.70 \\
(2.54) \\
\mathrm{a}\end{array}$ & $\begin{array}{c}15.24 \\
(2.52) \\
b\end{array}$ & $\begin{array}{c}14.82 \\
(3.98) \\
\text { B }\end{array}$ & $\begin{array}{c}15.75 \\
(5.18) \\
\text { B }\end{array}$ & $\begin{array}{c}97.00 \\
(10.35) \\
\beta\end{array}$ & $\begin{array}{c}125.85 \\
(23.52) \\
\beta\end{array}$ \\
\hline Ag-NPs & $\begin{array}{c}35.68 \\
(3.97) \\
b^{*}\end{array}$ & $\begin{array}{c}25.79 \\
(5.42) \\
a\end{array}$ & $\begin{array}{c}42.02 \\
(6.37) \\
C\end{array}$ & $\begin{array}{c}37.50 \\
(6.57) \\
C\end{array}$ & $\begin{array}{c}73.04 \\
(8.78) \\
\alpha^{*}\end{array}$ & $\begin{array}{c}63.64 \\
(3.37) \\
\alpha\end{array}$ \\
\hline
\end{tabular}

Same lower case indicates no statistical differences in nanoroughness between different treated dentin groups at intertubular dentin. Same capital letters indicates no statistical differences in nanoroughness between different treated dentin groups at peritubular dentin. Same greek letter indicates no statistical differences in fibrils width between different treated dentin groups. * indicates statistical differences between $24 \mathrm{~h}$ and 7 days storage groups.

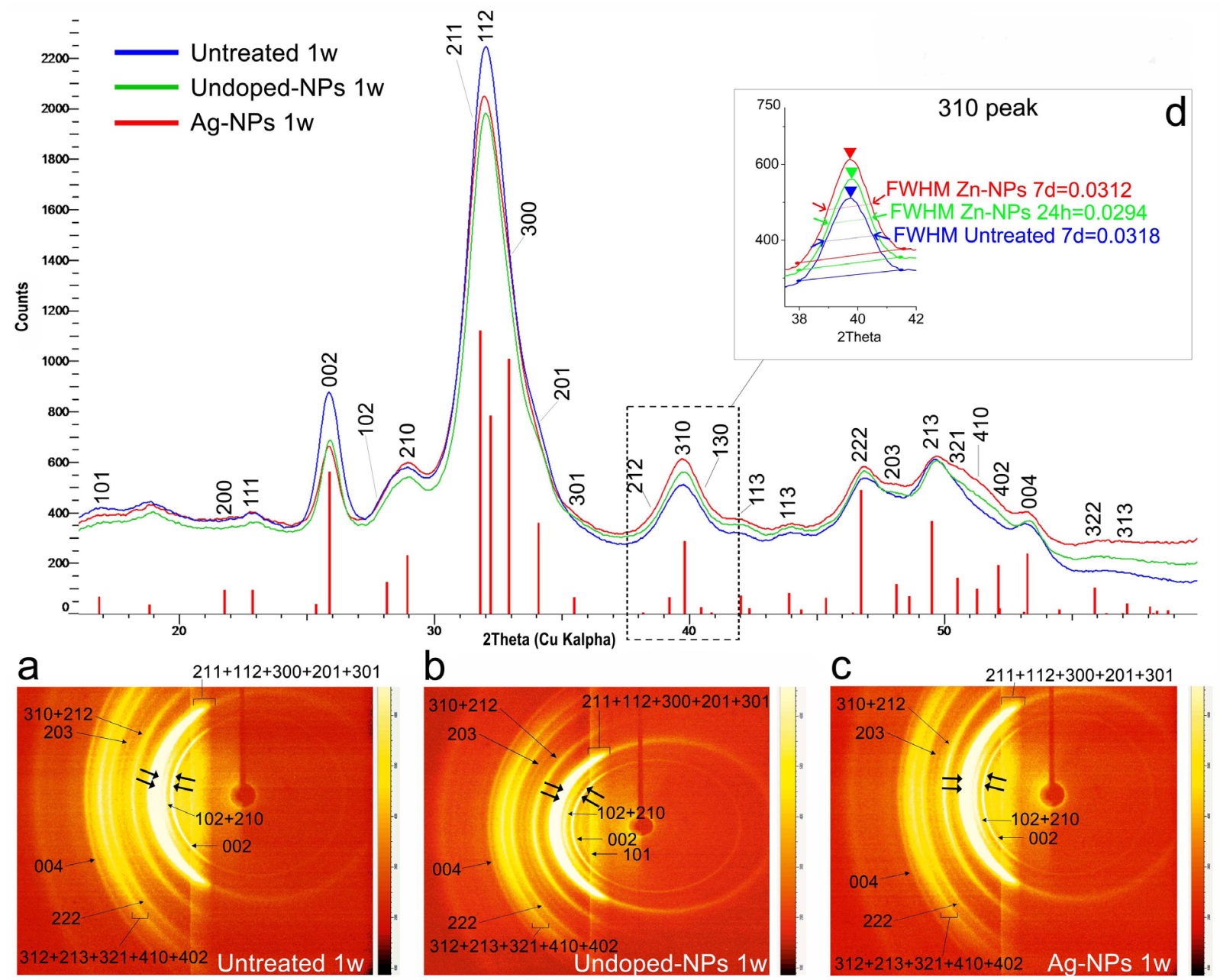

Fig. 2. Refined $\mu X \mathrm{XD}^{2}$ profiles of untreated, undoped-NPs and Ag-NPs treated dentin after $7 \mathrm{~d}$ of PBS storage. The corresponding DebyeScherrer rings are shown in inset a (untreated), b (undoped-NPs) and c (Ag-NPs). Double arrows mean strong diffraction rings. Vertical bars represent HAp peaks. Inset d represents a truncated $\mu \mathrm{XRD}^{2}$ profile after observing the reflection at 212, 310 and 130 peaks and further full width half maximum (FWHM) measurements after $7 \mathrm{~d}$. 
Table 3. Micro-X-ray diffraction pattern analysis approach of dentin surfaces after nanoparticles application.

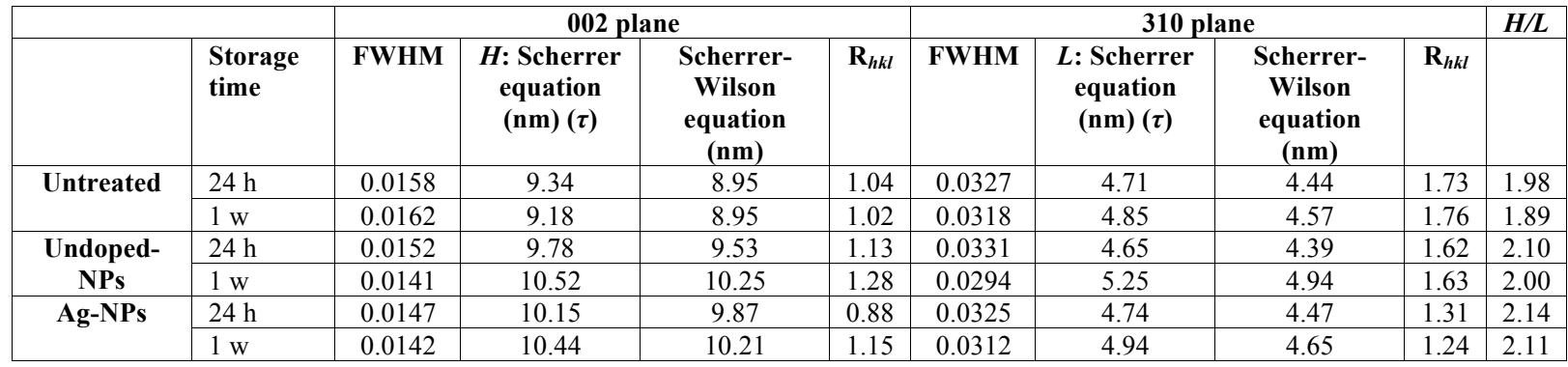

Abbreviations: Ag: Silver; NPs: Nanoparticles; FWHM: Full-width half-maximum.
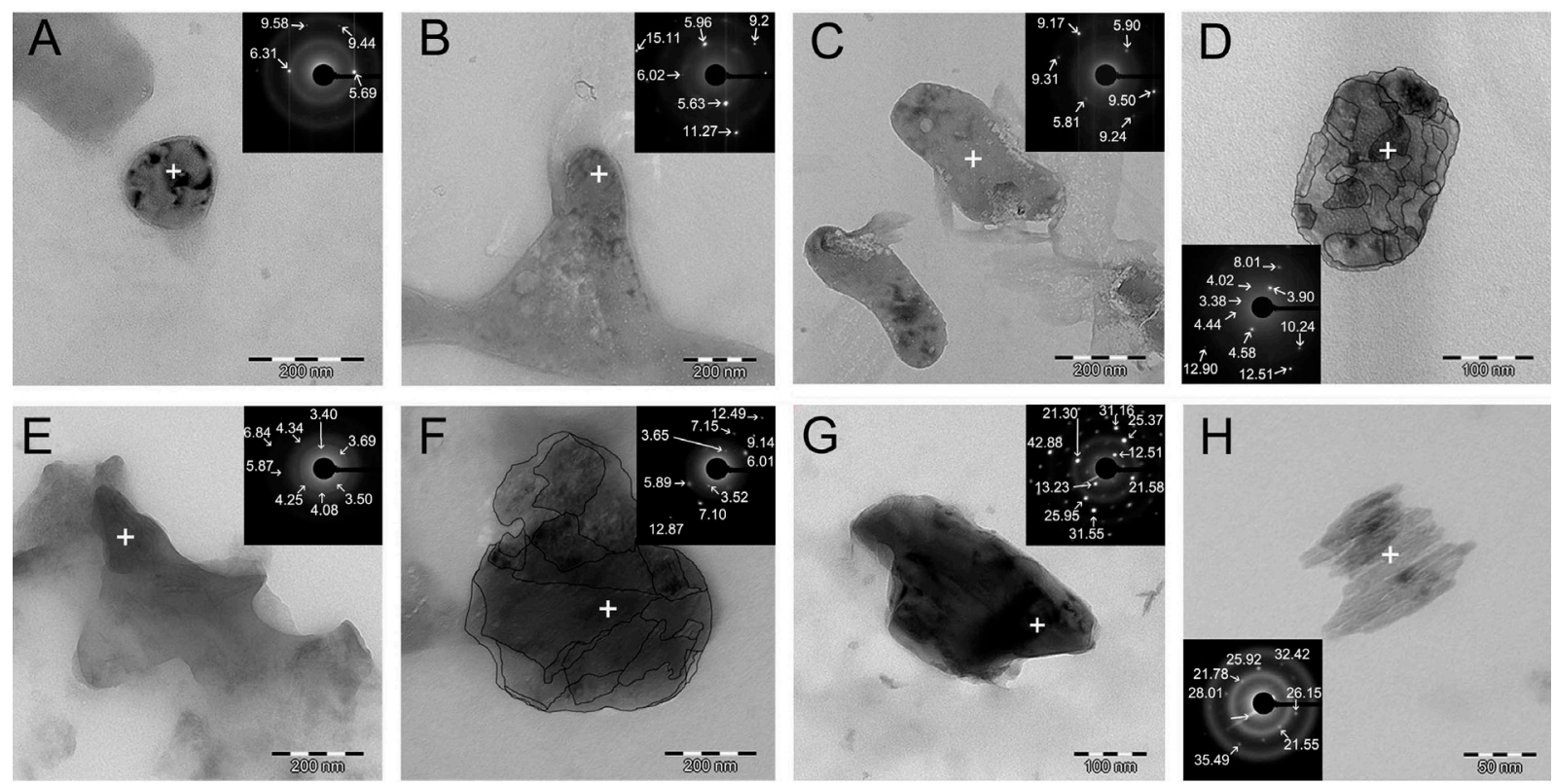

Fig. 3. (A,B), Bright-field of an assembly of block-like or rounded apatite crystals of cervical dentin treated with Ag-NPs, after $24 \mathrm{~h}$ storage. At the images at B, it is observed that the particles have a domain of locally aligned crystal arrays, showing the staggered order of polygon crystallites (scale bar: $200 \mathrm{~nm}$ ). (C,D), Bright-field of an assembly of rounded or hexagonal apatite crystals of cervical dentin treated with Ag-NPs, after $7 \mathrm{~d}$ storage. At the image D, it is observed that the particles have multiple domains of locally aligned crystal arrays with tendency to agglomerate. Profiles at D were highlighted to remark the overlapping [scale bar: $200 \mathrm{~nm}(\mathrm{C}), 100 \mathrm{~nm}$ (D)]. Insets (top right), which correspond to a selected area electron diffraction (SAED) d-values of micron and submicron size (+), are also shown. Diffractography depicts diffuse halo rings and d spacing values of submicron size crystals, in general. The diffraction patterns show diffuse halo rings indicating the presence of amorphous structure. (E,F), Bright-field of an assembly of polyhedral and rounded/drop-like apatite crystals of untreated cervical dentin, after $24 \mathrm{~h}$ and $7 \mathrm{~d}$ storage, respectively. At the image B, it is observed that the particles have multiple domains of locally aligned crystal arrays with tendency to agglomerate. Profiles at B were highlighted to remark the overlapping. (scale bar: $200 \mathrm{~nm}$, respectively). Diffraction pattern containing diffuse halo rings only, indicating some amorphous structure and clear d spacing values, meaning the presence of remnant crystallite matter. $(\mathrm{G}, \mathrm{H})$, Bright-field of an assembly of a polymorphic apatite crystals of cervical dentin treated with undoped-NPs based-gel, after $24 \mathrm{~h}$ and $7 \mathrm{~d}$ storage, respectively. The images show that the apatite crystal are made of overlapped order of the polycrystalline structure [scale bar: $100 \mathrm{~nm}(\mathrm{G}), 50 \mathrm{~nm}(\mathrm{H})$ ]. Images also exhibit that the particles have multiple domains. The labeled lattice planes of hydroxyapatite crystals, plate-like shaped, are clearly unveiled in H. Insets (top right), which correspond to a selected area electron diffraction (SAED) d-values of micron and submicron size (+), are also shown. Note that the spots are lightly delineated in these patterns, indicating polycrystalline structure. It also confirms the presence of hexagonal apatite.

better resolved peaks or peak broadening (3) parallel to the $c$-axes, indicated less amorphous HAp than that observed at the untreated group. Diffractography patterns gradually transform from broad diffuse peaks at cervical dentin treated with undoped-NPs or Ag-NPs at $24 \mathrm{~h}$, to sharper and more crystalline peaks after $7 \mathrm{~d}$
(Table 3) (Fig. 2). This confirms that amorphous phase itself is dynamic in nature. The SAED pattern observed in undoped-NPs (inset at Fig. 3H) revealed polycrystalline diffraction rings with interplanar spacing that was consistent with that of HAp (18).

The diffuse ring observed at SAED (Fig. 3D, inset) 
when dentin was treated with Ag-NPs indicated a decrease in crystallinity (19), probably amorphous calcium phosphate or octacalcium phosphate, contained within the apatite plates. This amorphous mineral can provide many active sites to attract $\mathrm{Ag}+$ ions, promoting the deposition of Ag-NPs on the mineral substrate (18). Nevertheless from analyzing the inset at figure 3D, it can be inferred the presence of other crystalline species such as HAp, silver sulfide (7), or even silver phosphate phase (20). After $7 \mathrm{~d}$, mean crystallite size along a direction parallel and perpendicular to the $c$-axis $[\tau 002$ $(\mathrm{H})]$ and $[\tau 310(\mathrm{~L})]$ of the dentin treated with Ag-NPs was $\sim 1.1$ and 1 folds higher respectively than those of untreated dentin. In the HAp crystals space structure, the $c$-plane contained more negatively charged group such as $\mathrm{PO}_{4}^{3-}$ ions and $\mathrm{OH}$ - ions, while the a-plane had more positively charged $\mathrm{Ca}^{2+}$ ions and consequently, more Ag-NPs may be attached at the $c$-plane (18). Apart from that, $\mathrm{H} / \mathrm{L}$ ratio increased in dentin treated with Ag-NPs more than in the rest of the groups (Table 3). This finding suggests a strong interaction of Ag-NPs with the HAp structure (21).

Texture is the distribution of crystallographic orientation of a polycrystalline sample. It accounts for changes in microstructure, proving a great influence on materials properties, as cracking resistance (22). For $\mathrm{R} \approx 1$, the grains were considered randomly oriented (23). The closest group to this criterion after $7 \mathrm{~d}$ of storage was the Ag-NPs, (R $h k l=1.24)$ (Table 3). After Ag-NPs treatment and $7 \mathrm{~d}$ storage, hexagonal nanoplate arrays, with regular and clear contour with tendency to agglomerate, were created, with a length reaching of $\sim 200 \mathrm{~nm}$ (Fig. 3D) and crystallite sizes of $10.44 \mathrm{~nm} \times 4.94 \mathrm{~nm}$ (Table 3). It is speculated that this morphology may be due to the effect of surrounding silver phosphate phase, $\mathrm{Ag}_{3} \mathrm{PO}_{4}$ (20). The predominant ring pattern corresponding to figures of two semi-circles instead of a continuous ring, when Ag-NPs were $7 \mathrm{~d}$ applied (Fig. 3D), show that the crystallites have preferred orientation in $c$-direction (2). These results indicate that Ag-NPs induced changes in the structure/ chemistry relationship that perform in synergistic manner. Therefore, the null hypothesis that was formulated in the present study must be rejected. There are several potential limitations of this study. Firstly, we measured dynamic rather than static nanomechanical properties. This new approach will throw light on whether AgNPs provokes definitive functional remineralization or not at cervical dentin, by measuring nanohardness and Young's modulus. Secondly, the extended time period of $7 \mathrm{~d}$ for this study was short. Within the limits of this study, it may be concluded that Ag-NPs had negative effect on the mechanical properties of cervical dentin, though the energy dissipation did not damage the dentin structure. Remineralization at dentin was not produced after Ag-NPs application, though improved crystal- linity may lead to increase stability of the apatite that was generated at the dentin surface. The present study, based on a new type of Ag-NPs, suggests a new class of nanomaterials for dental applications, with incorporated bactericidal effect.

\section{References}

1. Osorio R, Alfonso-Rodríguez CA, Medina-Castillo AL, Alaminos M, Toledano M. Bioactive Polymeric Nanoparticles for Periodontal Therapy. PLoS ONE. 2016;11:e0166217.

2. Toledano M, Toledano-Osorio M, Medina-Castillo AL, LópezLópez MT, Aguilera FS, Osorio R. Ion-modified nanoparticles induce different apatite formation in cervical dentine. Int Endod J. 2018;51:1019-29

3. Zhang Y, Zhai D, Xu M, Yao Q, Zhu H, Chang J, et al. 3D-printed bioceramic scaffolds with antibacterial and osteogenic activity. Biofabrication. 2017;9:025037.

4. Noronha VT, Paula AJ, Durán G, Galembeck A, Cogo-Müller K, Franz-Montan M, et al. Silver nanoparticles in dentistry. Dent Mater. 2017;33:1110-26

5. Zhu J, Liang R, Sun C, Xie L, Wang J, Leng D, et al. Effects of nanosilver and nanozinc incorporated mesoporous calcium-silicate nanoparticles on the mechanical properties of dentin. PLoS ONE. 2017; 12:e0182583.

6. Asmus SMF, Sakakura S, Pezzotti G. Hydroxyapatite Toughened by Silver Inclusions. J Compos Mater. 2003;37:2117-29.

7. Geng H, Poologasundarampillai G, Todd N, Devlin-Mullin A, Moore KL, Golrokhi Z, et al. Biotransformation of Silver Released from Nanoparticle Coated Titanium Implants Revealed in Regenerating Bone. ACS Appl Mater Interfaces. 2017;9:21169-80.

8. Dong Y, Liu W, Lei Y, Wu T, Zhang S, Guo Y, et al. Effect of gelatin sponge with colloid silver on bone healing in infected cranial defects. Mater Sci Eng C Mater Biol Appl. 2017;70:371-7.

9. Kwan KHL, Liu X, To MKT, Yeung KWK, Ho C, Wong KKY. Modulation of collagen alignment by silver nanoparticles results in better mechanical properties in wound healing. Nanomedicine. 2011;7:497-504

10. Medina-Castillo AL, Fernandez-Sanchez JF, Segura-Carretero A, Fernandez-Gutierrez A. Micrometer and submicrometer particles prepared by precipitation polymerization: thermodynamic model and experimental evidence of the relation between Flory's parameter and particle size. Macromolecules. 2010;43:5804-13.

11. Toledano-Osorio M, Osorio E, Aguilera FS, Luis Medina-Castillo A, Toledano M, Osorio R. Improved reactive nanoparticles to treat dentin hypersensitivity. Acta Biomater. 2018;72:371-80.

12. Toledano M, Toledano-Osorio M, Guerado E, Caso E, Osorio E, Osorio R. Assessing bone quality through mechanical properties in postmenopausal trabecular bone. Injury. 2018;49 Suppl 2:S3-10.

13. Ryou H, Pashley DH, Tay FR, Arola D. A characterization of the mechanical behavior of resin-infiltrated dentin using nanoscopic Dynamic Mechanical Analysis. Dent Mater. 2013;29:719-28.

14. Kinney JH, Marshall SJ, Marshall GW. The mechanical properties of human dentin: a critical review and re-evaluation of the dental literature. Crit Rev Oral Biol Med. 2003;14:13-29.

15. Toledano M, Osorio R, Osorio E, Medina-Castillo AL, ToledanoOsorio M, Aguilera FS. Ions-modified nanoparticles affect functional remineralization and energy dissipation through the resin-dentin interface. J Mech Behav Biomed Mater. 2017;68:62-79.

16. Gopalakrishnan V, Zukoski CF. Delayed flow in thermo-reversible colloidal gels. Journal of Rheology. 2007;51:623-44.

17. Agrawal R, Nieto A, Chen H, Mora M, Agarwal A. Nanoscale damping characteristics of boron nitride nanotubes and carbon nanotubes reinforced polymer composites. ACS Appl Mater Interfaces. 2013;5:12052-7.

18. Tian B, Chen W, Yu D, Lei Y, Ke Q, Guo Y, et al. Fabrication of silver nanoparticle-doped hydroxyapatite coatings with oriented block arrays for enhancing bactericidal effect and osteoinductivity. J Mech Behav Biomed Mater. agosto de 2016;61:345-59. 
19. Wang F, Guo E, Song E, Zhao P, Liu J. Structure and properties of bone-like-nanohydroxyapatite/gelatin/polyvinyl alcohol composites. Adv Biosci Biotechnol. 2010;1:185-9.

20. Rameshbabu N, Sampath Kumar TS, Prabhakar TG, Sastry VS, Murty KVGK, Prasad Rao K. Antibacterial nanosized silver substituted hydroxyapatite: Synthesis and characterization. J Biomed Mater Res. 2007;80A:581-91.

21. Bigi A, Boanini E, Gazzano M, Kojdecki MA, Rubini K. Microstructural investigation of hydroxyapatite-polyelectrolyte composites. J Mater Chem. 2004;14:274-9.

22. Liss K-D, Bartels A, Schreyer A, Clemens H. High-energy Xrays: a tool for advanced bulk investigations in materials science and physics. Textures and Microstructures. 2003;35:219-52.

23. Xue J, Zavgorodniy AV, Kennedy BJ, Swain MV, Li W. X-ray microdiffraction, TEM characterization and texture analysis of human dentin and enamel. J Microsc. 2013;251:144-53.

\section{Acknowledgments}

The authors wish to thank Mrs. Katherine García-Godoy for revising the text and her outstanding editing support.

\section{Funding}

This work was supported by the Ministry of Economy and Competitiveness (MINECO) [MAT2017-85999-P MINECO/AEI/FEDER/ UE] and European Regional Development Fund (FEDER). The authors have no competing interests to declare.

\section{Conflict of Interest}

All authors declare no conflict of interest. 